다 I프 IU 소

Jurnal Gentiaras Manajemen dan Akuntasi

Laman Jurnal: jurnal.gentiaras.ac.id/index.php/Gema/index

ISSN : 2086-9592 (p) , 2721-5490 (e)

\title{
Pengaruh Konflik Peran Ganda Terhadap Kinerja Karyawan Wanita dengan
}

\section{Stress Kerja Sebagai Mediasi}

\author{
Intan Kumala Sari ${ }^{1}$, Tania Rezki Farha ${ }^{1}$, Vicky F Sanjaya ${ }^{2}$ \\ 1. Jurusan Manajemen Bisnis Syariah, UIN Raden Intan Lampung, Lampung \\ 2. Fakultas Ekonomi dan Bisnis Islam, UIN Raden Intan Lampung, Lampung \\ *email: intanks278@gmail.com
}

\begin{tabular}{|c|c|}
\hline$A R T I C L E \quad I N F O$ & $A B S T R A C T$ \\
\hline $\begin{array}{l}\text { Artikel History: } \\
\text { Received: December 28, } 2020 \\
\text { Revised: January 31, } 2021 \\
\text { Published:February 9, } 2021\end{array}$ & $\begin{array}{l}\text { Work Family conflict is a conflict between family and work. This conflict arises because a } \\
\text { person plays two roles simultaneously where these roles can cause pressure at work and } \\
\text { cause stress at work. Research to determine the effect of Work Family conflict on the } \\
\text { performance of female employees and work stress as mediation. The variables used in this } \\
\text { research are work family conflict, performance, and work stress as mediation. The sample } \\
\text { used in this study were } 99 \text { female employee respondents. Hypothesis } 1 \text {, Work Family conflict } \\
\text { have a positive effect on work stress, the resulting } t \text { statistical value is } 8.712 \text { with a P value of } \\
0.000 \text {. Hypothesis } 2 \text {, Work stress has a negative effect on the performance of female } \\
\text { employees, the resulting } t \text { statistical value is } 1.724 \text { with a P value of } 0.085 \text {, Hypothesis } 3 \text {, } \\
\text { Work Family conflict has a negative effect on the performance of female employees, the } \\
\text { resulting } t \text { statistics value is } 0.957 \text { with a } P \text { value of } 0.339 \text {, hypothesis } 4 \text {, job stress mediates } \\
\text { the relationship between work family conflict and work stress of } 0.478408 \text { or } 47.8 \% \\
\text { (categorized as partial mediation). Contains research objectives, methods, research results. }\end{array}$ \\
\hline I N F O A R T I K E L & A B S T R A K \\
\hline $\begin{array}{l}\text { Riwayat Artikel: } \\
\text { Diterima: } 28 \text { Desember } 2020 \\
\text { Direvisi: } 31 \text { Januari } 2021 \\
\text { Dipublikasikan: } 9 \text { Februari } 2021\end{array}$ & $\begin{array}{l}\text { Konflik peran ganda adalah konflik antara keluarga dan pekerjaan konflik ini muncul karena } \\
\text { seseorang menjalani dua perannya secara bersamaan dimana peran tersebut bisa menimbulkan } \\
\text { tekanan dalam bekerja dan menyebabkan stress dalam bekerja. Penelitian ini dilakukan untuk } \\
\text { mengetahui pengaruh konflik peran ganda terhadap kinerja karyawan wanita dan stress kerja } \\
\text { sebagai mediasi.Variable yang digunakan dalam peneltian ini adalah konflik peran ganda, } \\
\text { kinerja, dan stress kerja sebgai mediasi. Sample yang digunakan dalam penelitian ini sebanyak } \\
100 \text { responden karyawan wanita. Hasil yang didapatkan adalah konflik peran ganda } \\
\text { berpengaruh positif terhadap stress kerja. Untuk variabel stress kerja berpengaruh negatif } \\
\text { terhadap kinerja karyawan wanita. Selain itu, konflik peran ganda berpengaruh negatif } \\
\text { terhadap kinerja karyawan wanita. Dan diketahui pula variabel stress kerja memediasi secara } \\
\text { parsial hubungan antara konflik peran ganda dan stress kerja sebesar } 0,478408 \text { atau sebesar } \\
47,8 \% \text {. }\end{array}$ \\
\hline
\end{tabular}




\section{PENDAHULUAN}

Konflik adalah sesuatu yang tidak dapat dihindari oleh setiap individu masing-masing untuk berbagai tingkat kepentingannya. Konflik ini bisa terjadi pada kehidupan setiap manusia dan tidak memandang umur dan gander, konflik ini bisa berdampak pada siapa saja. Frone (1992), indikatorindikator konflik keluarga-pekerjaan adalah tekanan sebagai orang tua, tekanan perkawinan, kurangnya keterlibatan sebagai istri, kurangnya keterlibatan sebagai orang tua, dan campur tangan pekerjaan.Peran serangkaian rumusan yang membatasi perilaku-perilaku yang diharapkan dari pemegang kedudukan tertentu (Wahab et al., 2019).

Wanita yang berkerja dan menikah biasanya akan mengalami konflik peran ganda, dikarenakan tugas yang dijalankan secara bersamaan. (Wahab et al., 2019). Konflik peran ganda sebagai konflik yang muncul akibat tanggung jawab yang berhubungan dengan pekerjaan mengganggu permintaan waktu dan ketegangan dalam keluarga.Konflik peran ganda terjadi dikarenakan karyawan berusaha menyeimbangkan tekanan yang muncul dari pekerjaan dan keluarga.

Kecenderungan pasangan suami istri yang berada di kota-kota besar saat ini adalah keduanya bekerja (dual career), yang diharapkan dapat mencukupi segala kebutuhan keluarga, termasuk biaya pendidikan anak. Menurut artikel CNN Indonesia, 36\% posisi senior di perusahaan dipegang oleh wanita. Survey tersebut menunjukkan sebesar 20\% posisi General Manager atau Office Manager dikendalikan oleh wanita. Tidak sedikit pula wanita yang memegang posisi lebih penting, seperti CEO, Direktur, CFO, dan COO.

Pada kenyataannya seorang karyawan yang telah menikah mereka akan memiliki dua komitmen utama didalam hidupnya, yaitu komitmen pada keluarga dan pekerjaannya (Nabila et al., 2019). Menurut Scoot (200) banyak kegagalan yang terjadi pada saat menyeimbangkan dan memenuhi kedua peranan tersebut. Ketidakseimbangan peran ini dapat memicu timbulnya suatu konflik peran ganda atau Work Family.

Konflik keluarga pekerjaan mengacu pada suatu bentuk konflik peran yang pada umumnya tuntutan waktu untuk keluarga, dan ketegangan yang diciptakan oleh keluargamengganggu tanggung jawab karyawan terhadap pekerjaan (Wahab et al., 2019). Karena pada saat menjalankan dua komitmen tersebut secara bersamaan karyawan wanita sering merasa dilema, sehinnga butuh waktu untuk menyeimbangkannya.Karena ketidakseimbangan antara keluarga dan pekerjan dapat menimbulkan terjadinya konflik peran ganda. 
Konflik peran ganda sering timbul karena pekerjaan yang memiliki jam kerja tidak fleksibel, tidak teratur, jam kerja yang panjang, serta beban kerja yang tinggi, stress pekerjaan yang dialami, konflik personal ditempat kerja, perjalanan dinas, perubahan karir, atau atasan oraganisasi yang tidak supportif dapat berpengaruh terhadap pelaksanaan tanggung jawab terhadap keluarga (Nabila et al., 2019). Keadaan ini dapat menggangu pikiran ataupun mental karyawan saat bekerja pada puncaknya, dapat menimbulkan stress kerja pada karyawan. Dengan kata lain, tuntutan yang datang dari pekerjaan dan keluarga melebihi kapasitas yang dimiliki karyawan tersebut dapat meningkatkan ketegangan setres dalam bekerja.

Stress kerja sebagai karyawan yang sudah menikah dan bekerja lebih banyak mengalami tingkat stress kerja yang lebih tinggi dibandingkan oleh seorang pria. Dikarenakan seorang wanita menjalani perannya sekaligus. Adanya konflik juga menjadi salah satu faktor stress yang bekepanjangan dapat mempengaruhi keadaan karyawaan (Fadhilah, 2020). Seperti konflik individu, karyawan satu dengan yang lainnya akan lebih mudah jika bekerja sama dalam menjalankan tugas, tetapi bila sedang ada konflik tertentu mengurangi perasaan puas terhadap hasil kerja. Deadline yang mendesak hal tersebut dapat berakibat stress yang berakibat pada fisik karena mengalami kelelahan yang berlebihan.

Kinerja merupakan suatu fungsi dari motivasi dan kemampuan. Untuk menyelesaikan tugas atau pekerjaan, seseorang harus memiliki derajat kesediaan dan tingkat kemampuan tertentu (Yasa, 2017). Kinerja merupakan kemampuan karyawan untuk melaksanakan pekerjaannya dengan baik atau tidak.Jika karyawan melaksanakann pekerjaan dengan baik berarti karyawan merasa puas dengan pekerjaannya (Susilo \& Wahyudin, 2020). Sebaliknya, jika karyawan memiliki kinerja yang buruk mereka tidak puas dengan pekerjaannya. Kinerja adalah hasil yang telah kita capai selama mengerjakan pekerjaan dalam kurun waktu tertentu yang sesuai dengan standar perusahaan yang diberikan. Selain mengetahui melalui penyelidikan kaitan konflik peran ganda berpengaruh secara positif terhadap stres kerja, maupun kinerja pada pegawai atau karyawan wanita, pada artikel ini membahas secara singkat kerja berperan sebagai pemediasi antara konflik peran ganda dan kinerja karyawan wanita atau pegawai wanita.

\section{METODE PENELITIAN}

\section{Desain Penelitian}

Di dalam penelitian ini, peneliti menggunakan desain survei dengan bantuan kuesioner yang dilakukan pada satu waktu tertentu. 


\section{Populasi dan Sampel}

Di dalam penelitian ini, peneliti mengambil 100 sampel yang merupakan karyawati atau karyawan wanita dari berbagai perusahaan yang sudah menikah. Ini dilakukan agar mendapatkan hasil yang dibutuhkan dengan mengambil sampel karyawan wanita dari berbagai macam profesi.

\section{Definisi Operasional}

Variabel yang peneliti gunakan meliputi variabel konflik peran ganda, variabel kinerja karyawan wanita, dan variabel stress kerja sebagai variabel mediasi. Di dalam variabel konflik peran ganda, peneliti menggunakan empat indikator yaitu kurangnya waktu untuk menjalankan masing-masing peran, kelelahan menjalankan satu peran karena peran lainnya, ketidakstabilan emosi pada satu peran ke peran lainnya, dan membawa masalah pada satu peran ke peran lain. Di dalam variabel stress kerja, peneliti menggunakan tiga indikator yaitu detak jantung meningkat, tekanan darah meningkat, dan absensi meningkat. Ini diambil dari sub variabel gejala fisik, gejala psikologis, dan gejala keprilakuan. Serta di dalam variabel kinerja karyawan wanita, peneliti menggunakan 3 indikator untuk mengukur besarnya pengaruh yaitu tingkat kepuasan terhadap mutu pekerjaan yang telah dilakukan, kemampuan menyelesaikan tugas sesuai dengan target, dan tidak menunda penyelesaian pekerjaan.

\section{Teknik Pengumpulan Data}

Teknik pengumpulan data yang dilakukan peneliti adalah melakukan penyebaran kuesioner kepada 100 responden karyawati yang telah menikah melalui bantuan media google form.

\section{Teknik Analisis Data}

Uji validitas yang digunakan peneliti adalah convergent validity dengan melihat nilai factor loading masing-masing item kuesioner. Uji reliabilitas dalam penelitian ini dengan melihat nilai Composite reliability dan nilai $A V E$ yang dihasilkan. Dan pengujian hipotesis menggunakan regresi linier sederhana.

\section{HASIL DAN PEMBAHASAN}

\section{Hasil Pengujian Kualitas Data (Outer Model)}

Outer model dalam sebuah penelitian merupakan suatu model pengukuran yang digunakan untuk menilai validitas dan reliabilitas model (Hartono dan Abdillah, 2009). Terdapat tiga kriteria di dalam penggunaan teknik analisa data dengan SmartPLS untuk menilai outer model yaitu Convergent Validity, Discriminant Validity, Composite Reliability dan Average Variance Extracted AVE (Nofi Sulistyowati, Akhmadi, and Lutfi 2017).

\section{a. Convergent Validity}

Convergent Validity dari model pengukuran dengan refleksif indikator dinilai berdasarkan korelasi antara item score atau component score yang diestimasi dengan software SmartPLS. Ukuran refleksif individual dikatakan tinggi jika berkorelasi lebih dari 0,70 dengan konstruk yang diukur. Dalam penelitian ini akan digunakan batas loading factor sebesar 0,70. Berikut adalah 
gambar hasil kalkulasi model SEM PLS, selanjutnya dilihat nilai loading factor indikator-indikator pada setiap variabel.

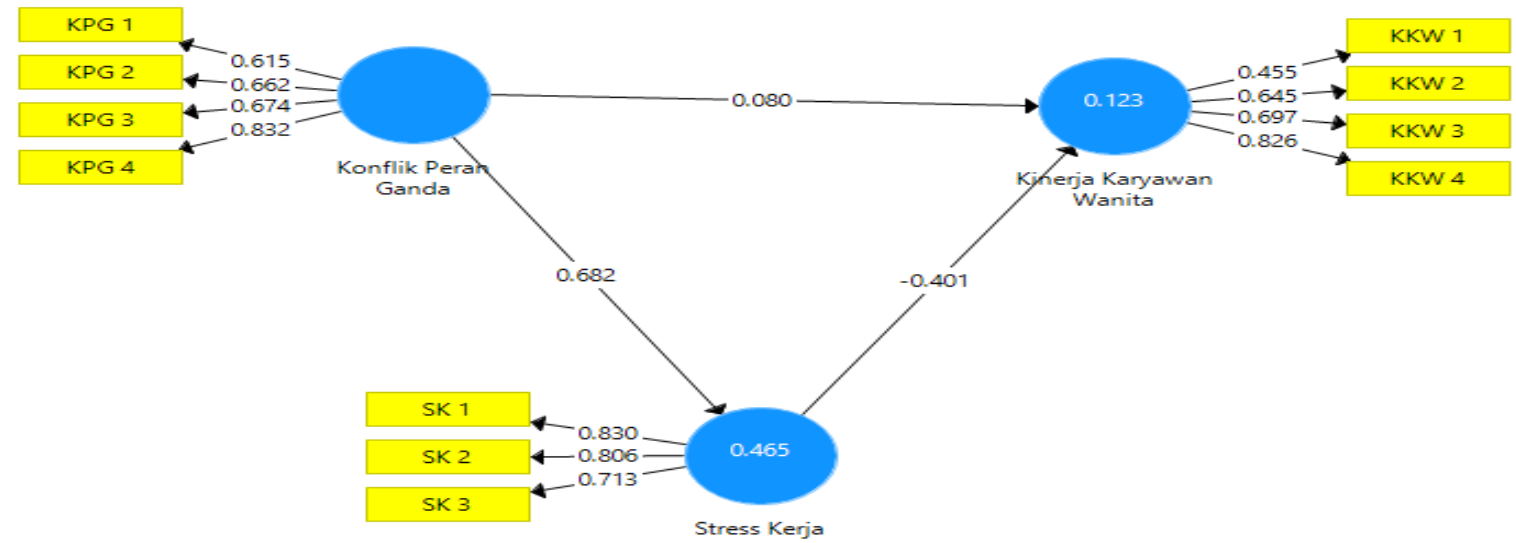

Gambar 1. Model Penelitian

Dalam SmartPLS, data dikatakan valid apabila nilai data indikator variabel $>0,70$. Berdasarkan hasil model pertama, terlihat bahwa terdapat hasil outer loading $<0,70$ atau tidak valid. Untuk mendapatkan hasil pengolahan data yang baik yaitu dilakukan dengan menghilangkan data yang tidak valid, dengan mengkonversi diagram jalur ke persamaan struktural tentang model struktural dasar dari inner model dan outer model.

Setelah menghilangkan data yang tidak valid, maka tampilan tabel outer loading dari model penelitian di atas adalah sebagai berikut:

Tabel 1.Outer Loading

\begin{tabular}{lccc}
\hline & $\begin{array}{c}\text { Kinerja } \\
\text { Karyawan } \\
\text { Wanita }\end{array}$ & $\begin{array}{c}\text { Konflik Peran } \\
\text { Ganda }\end{array}$ & Stress Kerja \\
\hline KKW 4 & 1.000 & & \\
KPG 4 & & 1.000 & 0.824 \\
SK 1 & & 0.818 \\
SK 2 & & & 0.705 \\
SK 3 & & & \\
\hline
\end{tabular}

Berdasarkan hasil pengolahan dengan menggunakan SmartPLS dapat dilihat pada Tabel 1, nilai outer model atau korelasi antara konstruk dengan variabel sudah memenuhi convergent validity. 


\section{b. Analisis Discriminant Validity}

Validitas diskriminan perlu dilakukan agar skala yang digunakan tidak memiliki dua konstruk yang mengukur hal yang sama. Discriminant validity dilakukan untuk memastikan bahwa setiap konsep dari masing-masing variabel laten berbeda dengan variabel laten lainnya.

\section{c. Mengevaluasi Reliability dan Average Variance Extracted (AVE)}

Kriteria validitas dan reabilitas juga dapat dilihat dari nilai reabilitas suatu konstruk dan nilai Average Variance Extracted (AVE)dari masing-masing konstruk. Konstruk dikatakan memiliki reabilitas yang tinggi jika nilainya 0,70 dan AVE yang berada di atas 0,50 (Ghozali, 2014).

Tabel 2. Composite Reliability dan Average Variance Extracted

\begin{tabular}{llll}
\hline \multicolumn{1}{c}{ Variabel } & \multicolumn{1}{c}{$\begin{array}{c}\text { Composite } \\
\text { Reliability }\end{array}$} & $\begin{array}{c}\text { Average } \\
\text { Variance } \\
\text { Extracted (AVE) }\end{array}$ & Keterangan \\
\hline Kinerja Karyawan Wanita & 1.000 & 1.000 & Reliabel \\
Konflik Peran Ganda & 1.000 & 1.000 & Reliabel \\
Stress Kerja & 0.827 & 0.615 & Reliabel \\
\hline
\end{tabular}

Berdasarkan Tabel 2, semua konstruk memenuhi kriteria reliabel. Hal ini ditunjukkan dengan nilai composite reliability di atas 0,70 dan AVE di atas 0,50. Nilai composite reliability dan cronbach's alpha yang disarankan adalah > 0.7 (Ghozali, 2014).

\section{Hasil Pengujian Kelayakan Model (Inner Model)}

Pengujian inner model dilakukan untuk melihat hubungan antara konstruk, nilai signifikansi dan R-square dari model penelitian. Berikut adalah hasil estimasi R-square dengan menggunakan SmartPLS:

Tabel 3. Nilai R-square

\begin{tabular}{lcc}
\hline \multicolumn{1}{c}{ Variabel } & R Square \\
\hline Kinerja Karyawan Wanita & 0.113 & \\
Stress Kerja & 0.395 & \\
\hline
\end{tabular}

Tabel 3 menunjukkan nilai R-square untuk variabel Kinerja Karyawan Wanita sebesar 0,113 dan untuk variabel Stress Kerja sebesar 0,395. Hasil ini menunjukkan bahwa sebesar 11\% variabel kinerja karyawan wanita dapat dipengaruhi oleh variabel konflik peran ganda dan stress kerja. Dan sebesar 39,5\% variabel stress kerja dapat dipengaruhi oleh variabel konflik peran ganda.

\section{Pengujian Hipotesis}

Dalam SmartPLS, pengujian secara statistik setiap hubungan yang dihipotesiskan dilakukan dengan menggunakan simulasi. Dalam hal ini dilakukan metode bootstrap terhadap sampel. Pengujian dengan bootstrap juga dimaksudkan untuk meminimalkan masalah ketidaknormalan data penelitian. Hasil setelah dilakukan pengujian dengan bootstraping menggunakan SmartPLS adalah sebagai berikut: 
Tabel 4.Path Coefficients

\begin{tabular}{llllll}
\hline \multicolumn{1}{c}{ Korelasi } & $\begin{array}{c}\text { Original } \\
\text { Sample } \\
(\mathbf{O})\end{array}$ & $\begin{array}{c}\text { Sample } \\
\text { Mean (M) }\end{array}$ & $\begin{array}{c}\text { Standard } \\
\text { Deviation } \\
(\mathbf{S T D E V})\end{array}$ & $\begin{array}{c}\text { T Statistics } \\
(|\mathbf{O} / \mathbf{S T D E V}|)\end{array}$ & P Values \\
\hline $\begin{array}{l}\text { Konflik Peran Ganda } \rightarrow \\
\text { Kinerja Karyawan Wanita }\end{array}$ & -0.135 & -0.121 & 0.141 & 0.957 & 0.339 \\
$\begin{array}{l}\text { Konflik Peran Ganda } \rightarrow \\
\text { Stress Kerja }\end{array}$ & 0.629 & 0.631 & 0.072 & 8.712 & 0.000 \\
$\begin{array}{l}\text { Stress Kerja } \rightarrow \text { Kinerja } \\
\text { Karyawan Wanita }\end{array}$ & -0.234 & -0.250 & 0.136 & 1.724 & 0.085 \\
\hline
\end{tabular}

\section{Hipotesis 1: Konflik Peran Ganda berpengaruh Positif terhadap Stress Kerja}

Uji terhadap konflik peran ganda dihasilkan nilai $T$ statistics 8,712 dengan $\mathrm{P}$ value sebesar 0,000. Dengan hasil tersebut, hipotesis yang diajukan dalam penelitian ini dapat diterima yaitu konflik peran ganda berpengaruh secara positif dan signifikan terhadap stress kerja.

\section{Hipotesis 2: Stress Kerja berpengaruh Negatif terhadap Kinerja Karyawan Wanita}

Uji terhadap stress kerja dihasilkan nilai $T$ statistics 1,724 dengan $\mathrm{P}$ value sebesar 0.085 . Dengan hasil tersebut, hipotesis yang diajukan dalam penelitian ini tidak dapat diterima yaitu stress kerja tidak berpengaruh terhadap kinerja karyawan wanita.

\section{Hipotesis 3: Konflik Peran Ganda berpengaruh Negatif terhadap Kinerja Karyawan Wanita}

Uji terhadap stress kerja dihasilkan nilai $T$ statistics 0,957 dengan $\mathrm{P}$ value sebesar 0,339. Dengan hasil tersebut, hipotesis yang diajukan dalam penelitian ini tidak dapat diterima yaitu konflik peran ganda tidak berpengaruh terhadap kinerja karyawan wanita.

\section{Hipotesis 4: Stress Kerja Memediasi Hubungan antara Konflik Peran Ganda terhadap Kinerja Karyawan Wanita}

Dengan menghitung nilai Variance Accounted For (FAV), kami mendapatkan nilai FAV sebesar 0,478408 atau sebesar 47,8\% (dikategorikan memediasi parsial). Dimana nilai tersebut sudah cukup untuk menentukan bahwa peran variabel stress kerja memediasi sebesar 47,8\% diantara hubungan konflik peran ganda dan kinerja karyawan wanita.Dengan demikian, hipotesis yang diajukan diterima yaitu stress kerja memediasi hubungan antara konflik peran ganda terhadap kinerja karyawan.

\section{KESIMPULAN}

Hasil pengujian terhadap hipotesis yang diajukan, diperoleh kesimpulan sebagai berikut:

1. Hipotesis pertama yang menyatakan konflik peran ganda berpengaruh positif terhadap stress kerja dapat diterima, artinya semakin tinggi konflik peran ganda maka stress kerja yang dialami karyawan wanita akan semakin tinggi atau meningkat pula. 
2. Hipotesis kedua yang menyatakan stress kerja berpengaruh negatif terhadap kinerja karyawan wanita tidak dapat diterima, artinya semakin tinggi stress kerja tidak menyebabkan kinerja karyawan wanita menurun.

3. Hipotesis kedua yang menyatakan konflik peran ganda berpengaruh negatif terhadap kinerja karyawan tidak dapat diterima. Artinya semakin tinggi konflik peran ganda tidak menyebabkan penurunan kinerja karyawan wanita.

4. Hipotesis keempat yang menyatakan stress kerja memediasi hubungan antara konflik peran ganda dan kinerja karyawan wanita dapat diterima. Dan dapat disimpulkan bahwa variabel stress kerja memediasi secara parsial sebesar $47,8 \%$.

Hasil yang didapatkan tersebut, dapat disimpulkan bahwa meskipun konflik peran ganda berpengaruh positif terhadap stress kerja karyawan, konflik peran ganda yang dialami karyawan wanita tidak selalu berdampak negatif terhadap penurunan kinerja karyawan wanita.

Penulis memberikan saran kepada, beberapa pihak terkait keterbatasan peneliti terhadap penelitian yang tertuang pada artikel ini, yaitu:

1. Bagi peneliti selanjutnya, agar menggunakan populasi sasaran yang lebih luas dan lebih banyak. Mengingat di dalam penelitian ini hanya menggunakan 100 responden saja.

2. Dari hasil analisis diketahui bahwa variabel stress kerja memediasi secara parsial, untuk itu akan lebih menarik apabila ditambahkan variabel-variabel lain yang belum ada di dalam penelitian ini yang berkaitan dengan konflik peran ganda dan kinerja karyawan wanita. Ini dilakukan agar nantinya mendapatkan hasil yang lebih baik.

3. Bagi pemangku kepentingan di perusahaan atau pimpinan, diharapkan agar memberikan konsentrasi khusus terhadap karyawan wanita yang telah menikah untuk meminimalisir tingkat stress kerja yang dialami karyawan wanita. Mengingat konflik peran ganda yang dialami karyawan wanita berdampak terhadap stress kerja yang dialami. Apabila tingkat stress kerja yang dialami semakin sedikit, maka peluang karyawan wanita untuk menyelesaikan pekerjaan secara maksimal akan semakin terbuka lebar.

\section{DAFTAR PUSTAKA}

Fadhilah U. Pengaruh Work Family Conflict dan Stres Kerja Terhadap Kinerja Karyawan PT. BPR Syari'ah Lantabur Tebuireng Jombang. 2020;2(2):351-369.

Nabila A, Nayati Utami H, Khurotul Aini E. Pengaruh Work Family Conflict Terhadap Kinerja Karyawan Melalui Stres Kerja ( Studi Pada Karyawan divisi Operational dan Servis pada PT . Bank BRI Syariah , Tbk Pusat ). J Adm Bisnis.2019;73(2):57-67. http://administrasibisnis.studentjournal.ub.ac.id/index.php/jab/article/download/2929/3314

Fadhilah, U. (2020). Pengaruh Work Family Conflict dan Stres Kerja Terhadap Kinerja Karyawan PT. BPR Syari'ah Lantabur Tebuireng Jombang. 2(2), 351-369. 
Nabila, A., Nayati Utami, H., \& Khurotul Aini, E. (2019). Pengaruh Work Family Conflict Terhadap Kinerja Karyawan Melalui Stres Kerja ( Studi Pada Karyawan divisi Operational dan Servis pada PT . Bank BRI Syariah , Tbk Pusat ). Jurnal Administrasi Bisnis (JAB), 73(2), http://administrasibisnis.studentjournal.ub.ac.id/index.php/jab/article/download/2929/3314

Nofi Sulistyowati, Akhmadi, \& Lutfi. (2017). Pengaruh Motivasi Ekstrinsik, Dan Lingkungan Kerja Fisik Terhadap Kinerja Karyawan Dengan Kepuasan Kerja Karyawan Sebagai Variabel Intervening. Jurnal Riset Bisnis Dan Manajemen Tirtayasa.

Susilo, Y., \& Wahyudin, W. (2020). Pengaruh Konflik Kerja Dan Stres Kerja Terhadap Kinerja Karyawan. EKOMABIS: Jurnal Ekonomi Manajemen Bisnis, 1(01), 45-58. https://doi.org/10.37366/ekomabis.v1i01.5

Wahab, A., Yasrie, A., \& Pengaruh, A. (2019). Pengaruh Konflik Peran Ganda Terhadap Kinerja Melalui Stress Kerja Sebagai Moderator Pada Pegawai Wanita. Jurnal Ekonomi Dan Bisnis, 12(2), 250-266.

Yasa, I. W. M. (2017). Pengaruh Konflik Peran Dan Ambiguitas Peran Terhadap Kinerja Pegawai Melalui Mediasi Stres Kerja Pada Dinas Kesehatan Kota Denpasar Bali. Jurnal Ekonomi Dan Bisnis, 4(1), 38-57. https://doi.org/10.22225/JJ.4.1.203.38-57 